\title{
A INFLUÊNCIA DA FAMÍLIA NA VIVÊNCIA DA SEXUALIDADE DE MULHERES ADOLESCENTES
}

\author{
The influence of the family in the experience of sexuality in adolescent girls \\ La influencia de la familia en la vivencia de la sexualidad de niñas adolescentes
}

Lúcia Beatriz Ressel $^{1}$

Carolina Frescura Junges ${ }^{2}$

GracielaDutraSehnem ${ }^{3}$

Cheila Sanfelice $^{4}$

\begin{abstract}
RESUMO
0 objetivo deste trabalho consistiu em identificar a influência da família na vivência da sexualidade de mulheres adolescentes. Tratase de uma pesquisa de campo, descritiva, com abordagem qualitativa cuja coleta de dados deu-se por meio de entrevista semiestruturada. As participantes da pesquisa foram 18 mulheres adolescentes. Aplicou-se a análise temática para a interpretação e a categorização dos dados. Os resultados apontaram para as seguintes categorias: 'sexo sem imprevistos: os pais falam sobre a prevenção'; 'a repressão da sexualidade: entre normas instituídas e acordos invisíveis'; e 'tornar-se mulher: os discursos disciplinadores sob o enfoque de gênero'. Verificou-se a necessidade de vislumbrar a atenção à saúde da mulher adolescente de maneira integral, enfocando os significados sociais e culturais atribuídos à sexualidade. Dessa forma, as atividades desenvolvidas pelos profissionais de saúde com mulheres adolescentes devem envolver a família, instituição promotora da singularização do indivíduo na sociedade.
\end{abstract}

Palavras-chave: Sexualidade. Adolescente. Família. Saúde da Mulher. Enfermagem.

\begin{abstract}
The following paper aims to identify the influence of family in the experience of sexuality in adolescent girls. It is a field descriptive research with a qualitative approach which data collection happened through semi-structured interview. The participants were 18 female adolescents. Theme analysis was applied to interpretation and categorizing data. The results pointed the following categories: 'sex without unexpected situations: parents speak about prevention'; 'the repression of sexuality: between instituted rules and invisible agreements'; and 'become a woman: disciplinary speeches focused on gender'. It is necessary to fully give attention to the health of adolescent women, focusing on the social and cultural meanings attributed to sexuality. This way, the activities developed by health professionals with female adolescents should involve the family, which promotes the singularity of the individual in the society.
\end{abstract}

Keywords: Sexuality. Adolescent. Family. Women's health. Nursing.

\section{Resumen}

El objetivo de este trabajo consistió en identificar la influencia de la familia en la vivencia de la sexualidad de niñas adolescentes. Se trata de una investigación descriptiva, con abordaje cualitativo, cuya recolección de datos ocurre a través de encuestas seme-estructuradas. Las participantes de la investigación fueron 18 niñas adolescentes. Se realizó un análisis temático para la interpretación y la categorización de los datos. Los resultados apuntaron para las siguientes categorías: "sexo sin imprevistos: los padres hablan sobre la prevención", "la represión de la sexualidad: entre normas instituidas y acuerdos invisibles", y "volverse mujer: los discursos disciplinarios bajo un enfoque de género". Se percibió la necesidad de darle la debida atención a la salud de la niña adolescente de forma integral con enfoque en los significados sociales y culturales atribuidos a la sexualidad. De esa forma, las actividades desarrolladas por los profesionales de la salud con niñas adolescentes deben involucrar la familia, que es la institución promotora de la singularización del individuo en la sociedad.

Palabras clave: Sexualidad. Adolescente. Familia. Salud de la Mujer. Enfermería.

${ }^{1}$ Doutora, professor adjunto do Departamento de Enfermagem e do Programa de Pós-graduação em Enfermagem (PPGEnf) da Universidade Federal de Santa Maria (UFSM). Líder do Grupo de Pesquisa "Cuidado, Saúde e Enfermagem". Santa Maria - RS. Brasil. E-mail: Ibressel208@yahoo.com.br ,'Enfermeira do Hospital Universitário da Universidade Federal de Santa Catarina (UFSC). Mestranda do PPGEnf - UFSM. Membro do Grupo de Pesquisa "Cuidado, Saúde e Enfermagem". Florianópolis-SC. Brasil. E-mail: cfjunges@hotmail.com ,'Enfermeira. Mestre em Enfermagem pela UFSM. Docente da Universidade Regional Integrada do Alto Uruguai e das Missões (URI) Campus de Santiago. Membro do Grupo de Pesquisa "Cuidado, Saúde e Enfermagem". Santa Maria-RS. Brasil. E-mail: graci_dutra@yahoo.com.br, "Enfermeira. Mestranda do PPGEnf - UFSM. Membro do Grupo de Pesquisa "Cuidado, Saúde e Enfermagem". Santa Maria-RS. Brasil. E-mail: cheilinha_sanf@yahoo.com.br 


\section{INTRODUÇÃO}

A adolescência constitui-se em uma fase singular da vida, que está conectada a experiências da infância e às potencialidades inerentes ao indivíduo adulto, o que a caracteriza como um período de significativas transformaç̃os. Essa transitoriedade apoia-se na proposição de que a maior parte das experiências dos adolescentes esteja ligada à preparação para o ingresso na vida adulta. No entanto, essa ideia é bastante controversa. Mesmo que o caráter de transição seja salientado nas discussões acerca da temática, concordamos que a adolescência não se limita às expectativas futuras. Afinal, os adolescentes vivem o seu próprio tempo, participando da vida social, trabalhando, votando e vivendo sua sexualidade. ${ }^{1}$

Adotamos neste estudo um conceito de adolescência mais expandido, que a evidencia para além do período do ciclo vital determinado cronologicamente. Assim, a adolescência é considerada "um período de vida em que há importantes transformaç̃oes físicas e mentais articuladas, em nossas sociedades, a um amplo redimensionamento de papéis sociais". 2:68 É preciso, portanto, ao trabalhar com os adolescentes, considerar as condições econômicas, políticas, sociais e culturais que determinam seus comportamentos individuais e grupais. ${ }^{3}$

A sociedade parece não compreender a adolescência como um período da vida que tem sentido em si mesma, uma vez que identifica os adolescentes em uma temporalidade que é projetada. ${ }^{1}$ Quando voltamos nosso olhar à adolescência nos concentrando apenas com o que ela acarretará para a vida adulta, há uma tendência à prescrição de comportamentos e atitudes que acabam por limitar essa fase do viver humano. Assim, durante sua trajetória, o ser adolescente passa por mudanças e enfrentamentos sociais, os quais poderão repercutir em sua vida, dependendo do contexto em que está inserido.

Nesta linha de pensamento, direcionamos nossa atenção às mulheres adolescentes, o que se justifica pela compreensão de que o processo de adolescer por elas vivenciado é, na maioria das vezes, caracterizado pela repressão de sua sexualidade; pela diferenciação de condutas e de controles impingidos diferentemente aos homens; pelos "nãos" que acenam aos limites constantes; pelas proibições; pela noção de inferioridade e de passividade, entre outros condicionamentos; bem como pela falta de diálogo e de esclarecimentos dos eventos biológicos, sociais e culturais que fazem parte de sua vida. ${ }^{4}$

Essas manifestações e normas comportamentais dirigidas às mulheres adolescentes repercutem diretamente na compreensão e construção de sua sexualidade. Compreendemos a sexualidade como um processo contínuo de aprendizado e descobertas. Ela está relacionada a todos os aspectos de nossa vida, sendo entendida, portanto, como o resultado de uma construção histórica, social e cultural singular, que se integra e se manifesta por meio da rede de significados do grupo social específico, possibilitando toda a expressão relativa ao sexo. ${ }^{5}$ Nesta direção, a família protagoniza como a precursora os valores sociais que repercutem no reconhecimento dessa dimensão na vida dos adolescentes.

Assuntos relacionados à sexualidade, até pouco tempo atrás, eram considerados tabus, limitados ao silêncio e até mesmo repreendidos no ambiente familiar. Hoje, esse tema já é conduzido de maneira transparente, em algumas famílias, por meio do diálogo e da busca por apoio profissional, quando necessário. Entretanto, ainda são encontradas marcas culturais perpetuadas através das gerações, em especial quando se refere à sexualidade feminina. ${ }^{6,7}$ Tais marcas remetem às condutas direcionadas às mulheres adolescentes que as limitam na vivência de sua sexualidade e que tratam o sexo e o prazer como algo proibido, perigoso e até mesmo pecaminoso. A família, assim, pode reforçar as ideias de que a sexualidade deve ser tratada de maneira sigilosa, e por vezes reprimida, ou possibilitar às adolescentes, por meio do diálogo, o reconhecimento da sua própria sexualidade com autonomia e responsabilidade. 5,8

Tendo em vista a relevância da temática e com intuito de contribuir nas demandas de tal realidade, o Curso de Enfermagem da Universidade Federal de Santa Maria (UFSM) implementou um Projeto de Ensino e Extensão denominado "Adolescer: crescer e viver". Tal iniciativa oportuniza às mulheres adolescentes espaços dialógicos e reflexivos com o intuito de elucidar a construção da mulher como sujeito de ação no mundo, pois, nesta fase de vida, são criados, reforçados e reproduzidos valores culturais estendidos na sua existência. Esta atividade é desenvolvida em escolas de ensino fundamental do município de Santa Maria/RS.

Como forma de ampliar o conhecimento obtido mediante ações já desenvolvidas com as adolescentes do projeto mencionado, foi realizada a pesquisa: A influência cultural na vulnerabilidade das adolescentes participantes do Projeto Adolescer, Crescer e Viver. ${ }^{4}$ Neste trabalho, apresentamos um recorte do estudo, objetivando conhecer a influência da família na vivência da sexualidade das adolescentes.

\section{METODOLOGIA}

Trata-se de uma pesquisa exploratório-descritiva, de abordagem qualitativa, realizada nos meses de dezembro de 2006 e março de 2007, com 18 adolescentes, com idade entre 12 e 15 anos, de duas escolas estaduais de ensino fundamental, participantes do projeto supracitado do Curso de Enfermagem da UFSM. Os critérios de seleção para composição da amostra constituíram-se em: ser mulher adolescente; participar do projeto de ensino e extensão; e aceitar livremente participar da pesquisa, com concordância dos pais ou responsáveis.

A coleta dos dados foi realizada por meio de entrevistas semiestruturadas, aplicadas individualmente, mediante agendamento prévio nas escolas em que as adolescentes estudavam. A entrevista constitui-se em um processo de 
interação social, no qual uma pessoa busca informações por intermédio de uma conversa com a outra. A entrevista semiestruturada combina perguntas fechadas e abertas, em que 0 entrevistado tem possibilidade de falar sobre o tema sem se prender à questão formulada..$^{9}$ Os questionamentos foram estimuladores para as participantes falarem sobre a sua compreensão de adolescência; saúde; doença; fatores de risco na adolescência e as condições de exposição a eles; hábitos de saúde; sexualidade e relacionamento familiar.

As questões éticas seguiram as orientações da Resolução n ${ }^{196 / 96}$ do Ministério da Saúde. ${ }^{10}$ A pesquisa foi aprovada no Comitê de Ética da UFSM, sob o protocolo n ${ }^{\circ} 047 /$ 05 , em 25 de julho de 2005. Além disso, com a finalidade de preservar a identidade das participantes, as falas foram identificadas pela letra $\mathrm{A}$, acompanhadas por numeração arábica. Os pais e as adolescentes assinaram os Termos de Consentimento Livre e Esclarecido e o Termo de Assentimento, conforme as normas para pesquisa com adolescentes.

A análise dos dados seguiu a orientação de Minayo para estudos na área das Ciências Sociais ${ }^{9}$ que inclui a ordenação e categorização dos dados a partir de um processo de leitura de todo o conteúdo, com registro consecutivo dos temas recorrentes, e a interpretação dos dados, a partir das aproximações com o referencial teórico do estudo.

\section{APRESENTAÇÃO DOS DADOS E DISCUSSÃO}

A seguir serão apresentados os dados que emergiram dos discursos das adolescentes com relação à vivência da sexualidade junto a suas famílias. Tais dados foram organizados nas seguintes categorias: "sexo sem imprevistos: os pais falam sobre a prevenção"; "a repressão da sexualidade: entre normas instituídas e acordos invisíveis"; e "tornar-se mulher: os discursos disciplinadores sob o enfoque de gênero".

\section{Sexo sem imprevistos: os pais falam sobre a prevenção}

É notável nos depoimentos das adolescentes o anseio de seus pais em protegê-las de prováveis riscos que relações sexuais desprotegidas podem expô-las. Essa abordagem da sexualidade pela família é restrita ao ato sexual e volta-se, prioritariamente, aos aspectos preventivos, o que pode ser observado nos discursos que ressaltam o uso de métodos contraceptivos.

A minha mãe sempre está ao meu lado, me orientando. Ela diz que, se eu for sair com alguém, é para usar camisinha, prevenindo uma gravidez.

Na minha família não falamos muito. A gente só fala sobre prevenção e o uso do preservativo.
A minha mãe fala, essas coisas de mãe, que eu tenho que me cuidar para não pegar barriga.

Ela (mãe) começou a dizer que eu estava pegando corpo. Depois contei que tinha mantido relações sexuais. Ela disse que agora vai pegar anticoncepcional para mim.

As adolescentes vivenciam a sua sexualidade de acordo com os valores apreendidos no meio familiar, pois é nesse ambiente que são, desde a infância, repassados ensinamentos e condutas aceitáveis para a socialização do indivíduo, compondo o seu universo simbólico. Dessa forma, é a partir de processos de socialização que o indivíduo interioriza os conteúdos da realidade subjetiva, tornando-se um membro da sociedade, onde vai atuar de acordo com os diferentes papéis sociais. Esta socialização ocorre em circunstâncias carregadas de alto grau de emoção, principalmente dentro da família. No decorrer desse processo, há identificação dos papéis sociais e das atitudes do grupo, tornando-os parte do indivíduo. Os conteúdos aí apreendidos são fixados automaticamente. ${ }^{11}$

A argumentação preventiva nos discursos parentais, em especial por parte da mãe, representa marcas de uma sexualidade velada, pouco falada e, nos momentos em que é trazida à tona, transparece tratar-se de um assunto perigoso, que pode trazer riscos e prejuízos. No entanto, percebemos nas falas que não há indicação de proibição ou negação para a vivência sexual, porém há destaque para a prevenção da gravidez, reforçando a responsabilização feminina pela sua ocorrência.

Os pais apresentam dificuldades em falar sobre sexualidade com suas filhas. Isso pode ser justificado pelo fato de que a sexualidade, apesar do período de transição em que vivemos, ainda é entendida como um evento permeado por mitos, tabus, proibições e silêncios. Falar sobre este tema era mais constrangedor para os pais de gerações anteriores, uma vez que a sexualidade era construída e alicerçada em valores muito mais rígidos. 5,8

Assim, a referência ao alerta de se cuidar pode ser interpretado para o sentido de se comportar, que traz codificado um sistema de valores culturais que normatiza os relacionamentos sociais, em especial nas condutas aceitáveis para a mulher adolescente em nossa sociedade., ${ }^{712}$

A oportunidade do diálogo entre pais e filhas é um espaço de trocas que pode possibilitar a discussão e a apreensão de orientações corretas que venham esclarecer e apoiar as filhas quanto ao próprio comportamento, no sentido de assegurar uma vivência saudável e sem temor em relação à sexualidade.

Outrossim, os depoimentos sugerem a existência de confiança na relação entre a mãe e as adolescentes. As falas reforçam a imagem materna de conselheira, parceira, cuidadora principal e responsável pelo preparo para a vivência da sexualidade das adolescentes dentro da família. Em geral, a 
responsabilidade do cuidado e da educação das crianças tende a ficar sob o domínio das mulheres, dentro do espaço privado, o lar, espaço das mães, que marca tipicamente os limites do mundo da criança. ${ }^{13}$

Por intermédio da mãe, a criança organiza sua relação com o mundo público; nessa intervenção são gradualmente construídos os limites e os controles, conduzidos pelos valores e pelas regras da sociedade em que ela vive. ${ }^{11} E$, portanto, por meio de seu relacionamento com os filhos que a mãe vai comunicando sua cultura.

\section{A repressão da sexualidade: entre normas instituídas e acordos invisíveis}

Percebemos, nas falas, a presença de uma postura repressiva que permeia o diálogo entre os pais e as filhas, podendo isso, por vezes, desencadear conflitos e, até mesmo, intimidar as adolescentes a procurar na família informações no que tange as questões relativas à sexualidade.

Meu pai me xinga e fala que não devo falar sobre esses assuntos. Minha mãe conversa com ele e pede para deixar de ser estúpido e conversar mais comigo.

Já fiquei com alguns meninos, mas foram todos escondidos. Eu tinha medo que meu paidescobrisse.

Às vezes discutimos (a adolescente e o pai) sobre esse assunto, e eu digo que não sou mais criança. Eu fico braba, eu sei o que é certo e o que é errado.

Nas falas, é evidente que a tentativa de conversar sobre a sexualidade e os relacionamentos afetivos parece ser abandonada antes mesmo de acontecer. Isso se deve ao temor representado pela figura paterna, a necessidade de esconder os fatos, de não falar sobre 0 assunto. Nesses momentos, a mãe novamente figura como mediadora, que busca dialogar e conduzir as relações entre o pai e as filhas, o que reitera a tradicional função materna que, além de alertar as filhas, converte-se em ponte das relações entre as filhas e o pai.

Quando os pais não reconhecem o amadurecimento da sexualidade de suas filhas desperdiçam a oportunidade de proporcionar espaços para a discussão sobre suas vivências e o esclarecimento de dúvidas. Além disso, falar com censura ou ser indiferente à sexualidade pode potencializar uma prática sexual insegura, desprovida de orientações ou baseada em informações inadequadas. ${ }^{14}$

Atualmente, o pai, apesar de estar participando com maior qualidade e frequência da vida dos filhos adolescentes, ainda ocupa um lugar periférico no que se refere às questões mais pessoais e de contato íntimo. Tal ocorrência pode estar associada ao fato de que a maioria dos adolescentes considera o pai como alguém que nem sempre os entende. Esta atribuição pode estar relacionada ao papel tradicionalmente atribuído à figura paterna, de disciplinador e provedor do sustento familiar em detrimento de uma maior exigência de envolvimento com questões afetivas. ${ }^{15,16}$

Percebemos que, para as adolescentes deste estudo, 0 pai representa mais uma figura disciplinadora e controladora e menos empática e permissível que a mãe.

Além disso, os pais podem sentir-se intimidados ao falar sobre sexualidade com suas filhas adolescentes, principalmente quando a sua educação sexual foi permeada por repressão. Tal dificuldade na comunicação familiar transparece as marcas de um discurso onde sexualidade era relacionada estritamente a reprodução. Torna-se importante, assim, que os pais reconheçam as diferenças históricas e culturais que interferem na vivência e no entendimento da sexualidade de seus filhos.

\section{Tornar-se mulher: os discursos disciplinadores sob 0 enfoque de gênero}

Algumas adolescentes expressaram existir controvérsias na maneira como é abordada a sexualidade entre filhos e filhas. Isso pode ser percebido quando o pai orienta às adolescentes um comportamento considerado aceitável para as mulheres, conforme valores familiares pré-estabelecidos por ditames de gênero.

Eu acho que ser guri tem mais vantagens. 0 pai acha bonito os guris (os irmãos) pegar as gurias porque, para ele, estão provando que são homens. Com eles meu pai é mais liberal

Meu pai diz que quando as pessoas veem a gente ficando com meninos, a gente fica mal falada na rua. Ele (pai) disse para nós namorarmos em casa.

0 compor tamento diferenciado dos pais em relação à criação das filhas e filhos interfere diretamente na formação da sua identidade e na postura que eles assumem em relação à sexualidade.

A construção de gênero em nossa sociedade ainda atribui valores que reforçam a submissão feminina, a postura recatada, cautelosa, tímida, além do controle sobre o corpo das mulheres, em contraste à representação da masculinidade que destaca a força, virilidade, rigidez, controle, privilegiando a ousadia e a liberdade. ${ }^{17}$

Ainda, corroborando os achados nessa pesquisa, é possível verificar que os adolescentes do sexo masculino se interessam mais precocemente pela iniciação sexual, são mais desinibidos e não se preocupam com as consequências que 0 sexo inseguro pode ocasionar, como as doenças sexualmente transmissíveis e a gravidez. Além disso, há motivação de pais e amigos para manterem relações sexuais como uma prova de masculinidade. Em contrapartida, as mulheres adolescentes 
são mais controladas pela família e apresentam temores em relação à gravidez e a doenças sexualmente transmissíveis, assim como, a partir do discurso dos pais, receiam os comentários gerados. ${ }^{7,16}$

0 homem e a mulher e, por extensão, os próprios conceitos de masculinidade e feminilidade tem sido definidos, em nossa sociedade, baseados em termos de oposição. Nesse sentido, a construção social de ambos se diferencia fortemente. Sob esse enfoque, os pais preocupam-se em corrigir qualquer sinal de comportamento inadequado, ou indisciplina, das filhas mulheres. ${ }^{13}$

Se, para a mulher, o controle e a rigidez das normas e condutas sociais é um percurso comum na socialização da sexualidade, para os homens, é dada mais liberdade, e até estimulado um comportamento arrojado e viril. Essa diferenciação carrega um dualismo moral explícito, que contribui para legitimar e reforçar a hierarquia de gênero. ${ }^{13}$

Mesmo que os discursos pontuem a diferenciação da dimensão biológica da social, a categoria de gênero manifesta que a sexualidade feminina foi historicamente construída de forma assimétrica e em oposição à masculina. Contudo, não é a diferença sexual que institui relações hierárquicas de modo assimétrico entre homens e mulheres, mas a maneira como cada sociedade valoriza e significa tais diferenças biológicas. Disso, decorrem representações sobre o que se espera do feminino e do masculino, de seus comportamentos e de suas atitudes, até mesmo sexuais. ${ }^{18}$

\section{CONSIDERAÇÕES FINAIS}

0 meio familiar propicia a criação da afetividade e segurança. Nesta instituição, as adolescentes tem a formação de valores enraizados para toda sua vida, sendo, portanto, determinante a maneira como a sexualidade é tratada. No decorrer da infância e parte da adolescência é que se firmam os valores culturais para homens e mulheres. É no convivio com os pais e demais familiares que se marca o padrão cultural da sexualidade. A partir daí, o comportamento feminino e 0 masculino são delineados em uma construção pertinente aos valores do seu grupo social.

Embora a socialização seja um processo dinâmico e contínuo ao longo da vida, é a socialização primária responsável pela internalização emocional dos eventos humanos. Nessa direção, entendemos a possível transformação individual, porém as vivências das adolescentes são carregadas de valores com alta impregnação emocional a partir da construção dos valores no seio familiar.

Vivemos em uma sociedade nitidamente marcada por valores e símbolos herdados do patriarcado. Conquanto tenha havido mudanças com a modernidade e com o processo de globalização cultural, ainda mantemos as raízes impregnadas na desigualdade da construção dos seres masculinos efemininos. Como fruto desse enraizamento cultural, vivenciamos as características comuns dessa socialização. Um claro exemplo é a maneira como está sendo construída a sexualidade feminina no grupo estudado, marcada por estratégias de alertas e prevenção a riscos.

Considerando os achados nesta pesquisa, destacamos a necessidade de vislumbrar a atenção à saúde do adolescente, enfocando a dimensão social em que vivencia a construção de seus valores. Nas atividades desenvolvidas pelos profissionais de saúde com adolescentes, deve-se atentar para a inserção de elementos éticos, biológicos, culturais e sociais nas discussões coletivas e no diálogo individualizado. Reiteramos que tais ações devem envolver a família, uma vez que essa instituição é a principal promotora da singularização do indivíduo na sociedade.

\section{REFERÊNCIAS}

1.Corti AP, Souza R. Diálogo com o mundo juvenil: subsídios para educadores. São Paulo: Ação Educativa; 2004.

2.Ayres JRCM, França Jl. Saúde do adolescente. In: Schriber L, et al, organizadores. Saúde do adulto: programas e ações na unidade básica. $2^{a}$ ed. São Paulo: Hucitec; 2000. p. 66-85.

3.Ramos FRS, Pereira SM, Rocha CRM. Viver e adolescer com qualidade. In: Adolescer: compreender, atuar, acolher. Projeto Acolher. Brasilia (DF): ABEn; 2001. p. 19-32.

4.Ressel LB. A influência cultural na vulnerabilidade das adolescentes participantes do Projeto Adolescer, Crescer e Viver [relatório de pesquisa] Santa Maria: Universidade Federal de Santa Maria; 2007.

5.Ressel LB. Vivenciando a sexualidade na assistência de enfermagem: um estudo na perspectiva cultural [tese]. São Paulo: Escola de Enfermagem, Universidade de São Paulo; 2003.

6.Sousa LB, Fernandes JFP, Barroso MGT. Sexualidade na adolescência: análise da influência de fatores culturais presentes no contexto familiar. Acta Paul Enferm. 2006; 19(4): 408-13.

7.Pelloso SM, Carvalho MDB, Higarashi IH. Sexualidade e gênero: um estudo com adolescentes em um município de pequeno porte do Noroeste do Paraná. Acta Sci, Health Sci. 2008; 30(2): 113-19.

8.Almeida ACCH, Centa ML. A família e a educação sexual dos filhos: implicações para a enfermagem. Acta Paul Enferm. 2009; 22(1): 71-6

9.Minayo MCS. 0 desafio do conhecimento: pesquisa qualitativa em saúde. $10^{a}$ ed. São Paulo: Hucitec; 2007.

10.Ministério da Saúde(BR) Conselho Nacional de Saúde. Resolução nº 196, de 10 de outubro de 1996. Diretrizes e normas regulamentadoras de pesquisa envolvendo seres humanos. Brasília (DF); 1996. 
A influência da família na vivência da sexualidade

11.Berger PL, Luckmann T. A construção social da realidade. Petrópolis (RJ): Vozes, 2009.

12.Ressel LB, Silva MJP. Reflexões sobre a sexualidade velada no silêncio dos corpos. Rev Enferm USP. 2001; 35(2): 150-54.

13.Parker RG. Corpos, prazeres e paixões: a cultura sexual no Brasil contemporâneo. São Paulo: Best Seller; 1991.

14.Cano MAT, Ferriani MGC. A família frente à sexualidade dos adolescentes. Acta Paul Enferm. 2000; 13(1): 38-46.

15.Wagner A, Falcke D, Silveira LMBO, Mosmann CP. A comunicação em famílias com filhos adolescentes. Psicol Estud. 2002; 7(1): 75-80.

16.Amaral MA, Fonseca RMGS. Entre o desejo e o medo: as representações sociais das adolescentes acerca da iniciação sexual. Rev Esc Enferm USP. 2006; 40(4): 469-76.

17.Baggio MA, Carvalho JN, Backes MTS, Backes DS, Meirelles BHS, Erdmann AL. Significado do papel masculino/feminino para adolescentes. Esc Anna Nery. 2009 out-dez; 13 (4): 872-78

18.Zucco LP, Minayo MCS. Sexualidade feminina em revista(s). Interface: comunicação, saúde e educação. 2009 jan/mar; 13(28): 43-54. 